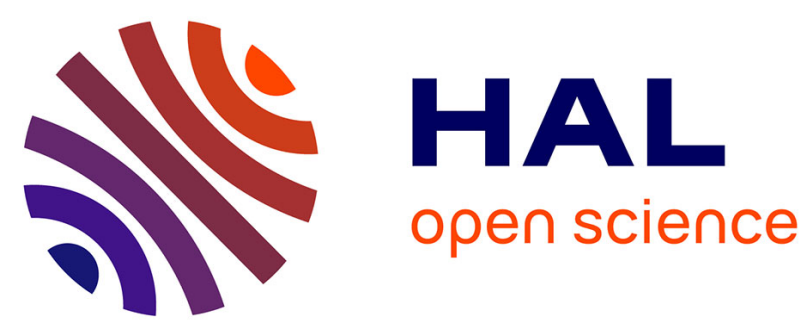

\title{
The Fourteenth International Workshop on Collaborative Editing Systems
}

Michael Macfadden, Agustina Agustina, Ning Gu, Claudia-Lavinia Ignat, Haifeng Shen, David Sun, Chengzheng Sun

\section{- To cite this version:}

Michael Macfadden, Agustina Agustina, Ning Gu, Claudia-Lavinia Ignat, Haifeng Shen, et al.. The Fourteenth International Workshop on Collaborative Editing Systems. The 17th ACM Conference on Computer supported cooperative work \& social computing, Feb 2014, Baltimore, United States. $10.1145 / 2556420.2558861$. hal-01088762

\section{HAL Id: hal-01088762 \\ https://hal.science/hal-01088762}

Submitted on 2 Dec 2014

HAL is a multi-disciplinary open access archive for the deposit and dissemination of scientific research documents, whether they are published or not. The documents may come from teaching and research institutions in France or abroad, or from public or private research centers.
L'archive ouverte pluridisciplinaire HAL, est destinée au dépôt et à la diffusion de documents scientifiques de niveau recherche, publiés ou non, émanant des établissements d'enseignement et de recherche français ou étrangers, des laboratoires publics ou privés. 


\section{The Fourteenth International Workshop on Collaborative Editing Systems}

Michael S. MacFadden

SOLUTE Consulting, USA

macfadden.michael@solute.us

\section{Agustina}

School of Computer Engineering,

Nanyang Technological University,

Singapore

agustina@ntu.edu.sg

\section{Ning Gu}

School of Computer Science,

Fudan University,

Shanghai, China

ninggu@fudan.edu.cn

Claudia-Lavinia Ignat

INRIA Nancy-Grand Est

France

claudia.ignat@inria.fr

Permission to make digital or hard copies of part or all of this work for personal or classroom use is granted without fee provided that copies are not made or distributed for profit or commercial advantage and that copies bear this notice and the full citation on the first page. Copyrights for third-party components of this work must be honored. For all other uses, contact the owner/author(s). Copyright is held by the author/owner(s)

CSCW'14 Companion, February 15-19, 2014, Baltimore, MD, USA ACM 978-1-4503-2541-7/14/02

http://dx.doi.org/10.1145/2556420.2558861

\section{Haifeng Shen}

School of Computer Science,

Eathematics,

\section{David Sun}

Department of Computer Science

and Electrical Engineering,

California,

\section{ngzheng Sun}

Nanyang Technological University,

czsun@ntu.edu.sg haifeng.shen@flinders.edu.au

\begin{abstract}
Interest in collaborative editing (CE) has seen a dramatic rise in recent years. The ubiquity of cloud services, crowdsourcing, and mobile devices means that today's Internet citizens are increasingly accustomed to producing and editing data in a shared network environment. While systems such as Google Drive, Microsoft Web Apps, Apache Wave and

Codoxware allow users to collaboratively edit shared information, they have just begun to scratch the surface of CE's full potential. In the coming years, users will expect to be able to collaboratively create, share, and edit documents and data in a dynamic, realtime, and intuitive manor. This workshop aims to connect researchers, developers, and users to help explore the future of CE in tomorrow's information landscape. This year's workshop focuses on how researchers and industry practitioners can work together to accelerate delivery of CE capabilities to meet the needs of the typical information-age user.
\end{abstract}

\section{Author Keywords}

Collaborative editing systems; groupware.

\section{ACM Classification Keywords}

C.2.4 [Computer-Communication Networks]:

Distributed Systems - Distributed applications; H.1.2

[Models and Principles]: User/Machine Systems - 
Human factors; H.4.1 [Information Systems

Applications]: Office Automation - Groupware; H.5.3 [Information Interfaces and Presentation]: Group and Organization Interfaces; I.7.1 [Document and text processing]: Document and text editing.

\section{General Terms}

Algorithms, Design, Human factors, Performance, Security, and Theory.

\section{Introduction}

Collaborative Editing (CE) technologies allow users to create and edit a wide array of shared content over computer networks. CE methods have been demonstrated to support a multitude of content types such as rich text documents, spreadsheets, 3D digital media design documents, virtual environments, and multimedia documents. CE techniques focus on the technical underpinnings to maintain consistency and integrity in shared information, and also facilitate a natural and intuitive collaboration environment by providing enhanced awareness of multiple users actions. Proper application of CE systems can lead to increased efficiency in creating shared content, improved team dynamics, and higher quality end products due to increased information exchange between collaborators.

Due to their traditional cost and complexity, implementations of CE Systems have historically been the domain of seasoned computer professionals, academic researchers, and large corporations. However, many of today's average technology consumers have persistent Internet connections, extensive web experience, and mobile Internet enabled devices. Internet users are increasingly creating and sharing content through cloud services and social media sites. As users migrate their content from personal computers and storage devices to hosted services in the cloud, it has become more natural for users to share and work with each other's content. Whether it simply is tagging each other photo's on Facebook, contributing to articles in Wikipedia, or collaboratively editing documents on Google Drive, users are beginning to expect to share and modify their content in a collaborative mode.

Many of these products offer only limited collaborative functionality, including locking, asynchronous, non-realtime collaboration where only one user is able to edit a shared document at any given time. Many services also lack intuitive collaboration awareness functionality to allow users to work together effectively. Meanwhile, over the past $20+$ years many research efforts have studied various key technical and social issues surrounding CE. Examples of social and technical issues in $C E$ include the impact of culture or organizational roles on $\mathrm{CE}$, melding of real-time and non-real-time $\mathrm{CE}$ in social interaction, privacy and security, consistency maintenance, group undo, group awareness, interaction control, and syntactic/semantic conflict resolution. Significant attention has been given to algorithmic and human factors techniques that allow users to freely and concurrently modify shared documents while minimizing and resolving conflicts. These efforts have demonstrated and documented several effective techniques relevant to user's needs of collaborative systems.

While in recent years commercial industry's participation in the CE domain has steadily increased, it has not kept pace with many users' expectations. 
Several products such as Google Drive, Novell Vibe, and Codoxware have proven that CE functionality can greatly increase the usability and user impression of mature products. These systems have begun to raise the general public's awareness of CE and demonstrated the marketability of CE functionality. These systems, however, have only begun to scratch the surface of the market and there exists a great opportunity to both increase the capability of CE systems as well increase ability to reach end users.

\section{Workshop Theme}

This workshop builds on the success of the previous thirteen annual workshops. The theme of each workshop evolved over time to focus on the current issues surrounding collaborative editing based on new research, technological advancements in computing and networking, and socio-technological changes impacting the way users interact with computer supported collaboration systems.

Last year's workshop, IWCES13 held at CSCW'12, focused on traditional technical CE topics such as theoretical foundation, algorithm design, and system/application development but in the context of complex document formats such as rich text, html/xml, spreadsheet, 2D/3D digital media, CAD, video, etc. Specific focus was given to a discussion of user requirement analysis, evaluation, and usability studies of CE systems for complex real-world problems.

To maintain the momentum generated by IWCES13, this year's workshop will focus on aligning the interests of end users, industry product developers, and academic researchers to accelerate the incorporation of collaborative editing features in future services. As users are pushing their data in to the cloud, there is a growing demand for lively, real-time collaboration features. The goal of the workshop is to discuss the latest research findings, review CE adoption within industry, and analyze users' expectations. Through a continuing and open dialogue we hope to facilitate transition of research results to industry, to better understand the needs and expectations of users, and to identify new areas of required research that can aid in future adoption. Topics of discussion will be a mix of technical, social, usability, and commercial implications of CE.

\section{Workshop Participation}

We encourage participation from academic and industry practitioners interested in researching various aspects of CE. Participation from industry representatives who have experience and interest in building real-world CE systems is also encouraged. Finally we welcome human factors experts, interface designers, social interaction researchers, and end-users that are interested in novel applications of CE.

Each participant is requested to submit a position paper describing the presentation or discussion they wish to contribute to the workshop. While not mandatory, those prospective participants submitting a position paper will be given priority if space becomes limited. We invite submissions pertaining to all topics relevant to CE and CE systems. Each position paper should contain 2-6 pages summarizing the content to be presented and/or discussed. While certainly not required, if your topic pertains to a system and that system is easily demonstrated, a demonstration is encouraged. All papers should be formatted using the standard ACM SIGCHI format and should include an 
abstract of no more than 150 words. Topics of interest include, but are not limited to:

- Concurrency control and consistency maintenance

- Group undo and conflict resolution

- Correctness, performance and scalability of CE methods

- Novel collaboration awareness concepts for avoiding conflicts in CE systems

- Implementation of CE techniques in new application domains

- Human factors, social impacts of CE Systems

- Evaluation, usability studies, and empirical studies of CE systems

- $\quad$ Privacy and security issues in CE systems

- New and emerging requirements for CE.

- Visions for the future of CE.

All submissions should be emailed to Michael MacFadden at macfadden.michael@solute.us. Submissions will be reviewed by the workshop organizing committee based on relevancy, novelty, and quality. Accepted papers will be published online on the workshops web site. It is required for at least one author of an accepted paper to register and attend the workshop in order to present the material.

\section{Workshop Agenda}

The proposed workshop will be a full-day event. The workshop agenda will contain presentations from participants, focused discussion sessions, and an open forum session. The workshop will likely attract 15-20 participants.

\section{Important Dates}

- Paper submission: November 22, 2013.

- Notification of acceptance: December 6, 2013.

- Workshop: February 2014. 